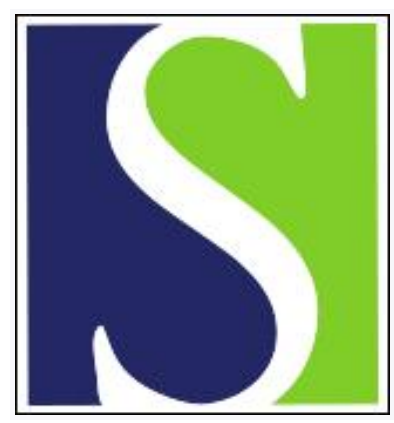

Scand J Work Environ Health 2002;28(1):64-71

https://doi.org/10.5271/sjweh.648

Issue date: Feb 2002

Shift work and age as interactive predictors of body mass index among offshore workers

by Parkes KR

Affiliation: Department of Experimental Psychology, University of Oxford, South Parks Road, Oxford, OX1 3UD, United Kingdom. kathy.parkes@psy.ox.ac.uk

Refers to the following texts of the Journal: 1999;25(2):100-104

1998;24(5):351-357 1999;25(2):85-99 2001;27(2):85-86

$1999 ; 25(6): 610-615 \quad 2001 ; 27(2): 87-96 \quad 1998 ; 24(5): 321-333$

$1997 ; 23(4): 241-242 \quad 2001 ; 27(2): 97-105$

The following articles refer to this text: 2004;30(2):149-156;

2007;33(1):45-50; 2008;34(1):33-39; 2009;35(4):309-318;

2011;37(4):263-275; 2015;41(3):259-267

Key terms: age; body mass index; body weight; demographic factor; health behavior; job type; night work; occupation; offshore worker; shift work; smoking

This article in PubMed: www.ncbi.nlm.nih.gov/pubmed/11871855

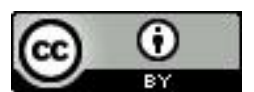




\title{
Shift work and age as interactive predictors of body mass index among offshore workers
}

\author{
by Katharine $R$ Parkes, $P h D^{1}$
}

Parkes KR. Shift work and age as interactive predictors of body mass index among offshore workers. Scand J Work Environ Health 2002;28(1):64-71.

\begin{abstract}
Objectives This study investigated shift pattern (day shifts versus day-night rotation) and its interactions with age, and with years of shiftwork exposure, as predictors of body mass index (BMI).

Methods Survey data were collected from offshore personnel working day shifts $(\mathrm{N}=787)$ or day-night shifts $(\mathrm{N}=787)$; information was obtained about shift pattern and years of shiftwork exposure, height, weight, demographic factors, and smoking habits. Hierarchical multiple regression was used to test a model in which BMI was predicted by additive and interactive effects of shift pattern, age, and exposure years with control for confounding variables.

Results In a multivariate analysis (controlling for job type, education and smoking), BMI was predicted by the main effects of age and years of shiftwork exposure. Shift pattern was not significant as a main effect, but it interacted significantly with the curvilinear age term and with the linear and curvilinear components of shiftwork exposure. In the day shift group, age but not exposure predicted BMI; the opposite was true of the day-night shift group. The increase in BMI with an increase in age and exposure years was steeper for the day-night shift group than for the day shift group.

Conclusions The significant interaction effects found in this study were consistent with the view that continued exposure to day-night shift work gives rise to increases in BMI, over and above the normative effects of ageing on BMI shown by day-shift workers.
\end{abstract}

Key terms body weight, demographic factors, health behavior, job type, night work, occupation, offshore, smoking.

High levels of body mass index (BMI) are not only associated with serious diseases and general health impairment, but also with accidents and injuries at work (13 ). However, although demographic factors (particularly age) and life-style variables have been widely studied as predictors of BMI (4-6), occupational factors have received less research attention. Stress at work, whether psychosocial or ergonomic, appears to play only a minor role $(3,7)$, but significant positive relationships between long workhours and BMI have been reported (8). More directly relevant to the present study, shift work (particularly night work) has also been investigated in relation to BMI.

Niedhammer et al (9) found little existing evidence that shift patterns involving night work had significant effects on BMI. In their data, weight gain of more than 5 kilograms over a 5-year period (1985-1990) was marginally more prevalent $(\mathrm{P}<0.10)$ among female nurses exposed to night work (as compared with day work) over the intervening years, but an analysis of the previous 5-year period did not produce similar results. A more recent small-scale study of nurses found that, as compared with day workers $(\mathrm{N}=36)$, those working evening or night shifts $(\mathrm{N}=49)$ retrospectively reported greater weight gain after starting to work the shift pattern (10), although current weight did not differ between the two groups. Other evidence indicates a positive relationship between BMI and duration of shiftwork exposure, with control for age (11); in particular, employees exposed to shift work for more than 5 years had a significantly higher BMI than those with no shiftwork experience.

Changes in life-style, particularly dietary habits (such as eating fewer meals and more snacks), have been suggested as explanations for findings linking shift work and BMI (12). Consistent with this view, Geliebter et al (10) found that nurses working late-evening or night shifts reported changed patterns of eating and exercise

1 Department of Experimental Psychology, University of Oxford, Oxford, United Kingdom.

Reprint requests to: Dr KR Parkes, Department of Experimental Psychology, University of Oxford, South Parks Road, Oxford, OX1 3UD, United Kingdom. [E-mail: kathy.parkes@psy.ox.ac.uk] 
which were associated with changes in shift schedule. Other recent evidence suggests that shiftworkers take smaller amounts of energy and nutrients than day workers (13), although findings demonstrating changes in the circadian distribution of food intake, but not in total 24hour consumption, have also been reported (14). Taken together, these results suggest that changed eating habits, and other life-style changes (including reduced exercise), among night shift workers may lead to increases in BMI, which, in turn, contribute to the higher levels of hypertension (15) and cardiovascular risk (16-18) associated with day-night shift work. However, the biological mechanisms that underlie observed relationships between shift work and cardiovascular risk have, as yet, not been clearly established (19).

The limited information currently available, and the possibility that increased BMI is implicated in relations between shift work and cardiovascular disease, suggests further research is needed into links between BMI and shift patterns. Two relevant issues are addressed in this report. First, there is the question of whether the magnitude of the effect of shift schedules involving night work on BMI is dependent on age or years of exposure to shift work or on both these factors. Adaptation to shift work is known to become more difficult with increasing age (20-23), and duration of shiftwork exposure is related to BMI over and above the effects of age (11). These findings suggest that, as compared with day shifts, day-night shifts may give rise to a progressive BMI increment that depends on both age and exposure years. Thus, not only the main effects of age and exposure years, but also the interactions of these variables with shift patterns would be expected to predict BMI. The present study tests this model, while taking into account several potential confounding factors.

Second, previous studies of shiftwork and BMI have not examined curvilinear effects of age and duration of shiftwork exposure, although epidemiologic research indicates that the relation between age and BMI is not purely linear $(4,24)$, and the duration of shiftwork exposure may follow a similar pattern. Thus, in this study, the possible curvilinear effects of age and shiftwork exposure were examined by evaluating their linear and quadratic effects in relation to BMI.

\section{Sample and methods}

\section{Data collection}

Survey data were collected in 1995 from offshore personnel working on 17 oil and gas installations in the United Kingdom (UK) sector of the North Sea. All data were collected by researchers visiting the installations concerned. Further details of the data collection have been reported elsewhere $(25,26)$. A total of 1598 male personnel completed questionnaires; response rates varied across the 17 installations in the study, with an average of $82.6 \%$ (range $67.2 \%-98.0 \%$ ). Listwise deletion of missing data reduced the analysis sample to 1574 men.

\section{Measures}

Age and duration of shiftwork exposure were recorded in years. The mean age was 38.7 (SD 8.9, range 19-63) years. The mean duration of shiftwork exposure was 12.9 (SD 8.0) years, the range being 2 months-46 years.

All personnel worked 12-hour shifts. Day shift workers were coded $0(\mathrm{~N}=787)$; day-night shift workers were coded $1(\mathrm{~N}=787)$. The latter group consisted primarily of personnel who worked rotating shift patterns with an equal number of day and night shifts, but it also included a small number who did predominantly night work. The typical day-night rotation pattern was 7 night shifts and 7 day shifts, followed by 14 days of shore leave. Day shift personnel worked 14-day shifts followed by 14 days of shore leave. Day shifts normally ran from 0700 to 1900 for both day shift and day-night shift personnel, and night shifts were from 1900 to 0700 ; each shift had a 1-hour midshift meal break.

Participants were asked to record their job titles and to indicate their main area of work. The following eight job types (which covered all occupational groups offshore) were identified: management $(11.2 \%, \mathrm{~N}=176)$, technical $(7.6 \%, \mathrm{~N}=119)$, maintenance $(25.8 \%, \mathrm{~N}=406)$, production $(14.7 \%, \mathrm{~N}=232)$, drilling $(17.1 \%, \mathrm{~N}=270)$, construction $(8.7 \%, \mathrm{~N}=137)$, administration $(7.3 \%$, $\mathrm{N}=115)$, and catering $(7.6 \%, \mathrm{~N}=119)$.

Education was coded in terms of the highest qualification level reported. The following three levels were identified: level 1: certificate of secondary school education, or equivalent $(17.8 \%, \mathrm{~N}=280)$; level 2: technical certificates and college diplomas $(51.8 \%, \mathrm{~N}=815)$; and level 3: advanced level examinations or university degree or both $(12.2 \%, \mathrm{~N}=193)$. In addition, $18.2 \%$ $(\mathrm{N}=286)$ of the personnel reported no formal qualifications (level 0).

The participants were asked whether they were current smokers. Their responses were coded as 0 (nonsmoker) and 1 (smoker). The percentage of smokers was $36.0 \%(\mathrm{~N}=566)$.

BMI was calculated by dividing weight in kilograms the square of height in meters.

\section{Statistical analysis}

Multiple regression was used to examine the extent to which BMI was jointly predicted by shift pattern and years of exposure after control for demographic factors and smoking habits. The independent predictors were 
age and years of shiftwork exposure (treated as continuous variables) and shift pattern, educational level, smoking habits, and job type (categorical variables). To facilitate interpretation of the regression coefficients, continuous variables were standardized prior to analysis; dummy coding was used for categorical variables. The analysis was carried out in three hierarchical stages. First, a simultaneous additive model (which included the main effects of shift pattern and years of exposure, together with age and the control variables) was evaluated. Second, quadratic terms representing the curvilinear effects of age and shiftwork years were entered. Third, the terms representing the predicted linear and curvilinear interactions of shift pattern with age and exposure years were entered. The analysis was carried out using the SPSS General Linear Model procedure; it followed standard regression methods for testing curvilinear and interactive terms $(27,28)$.

\section{Results}

\section{Mean body mass index}

The overall mean BMI value was 25.6 (SD 2.8) [mean age 38.7 (SD 8.9) years]. This value agreed closely with the predicted value (25.65) calculated for the present sample by applying the regression equation relating BMI to age in data from 419 offshore workers [mean age 32.5 (SD 8.2) years, mean BMI 24.8 (SD 2.8)] derived by Light \& Gibson (29). However, these authors included only the linear regression term, whereas the present regression analysis had significant linear $(\mathrm{P}<0.001)$ and quadratic $(\mathrm{P}<0.025)$ components.

\section{Obesity and overweight}

Of the men in this study, $7.5 \%$ were obese (BMI >30) and $47.2 \%$ were overweight (BMI 25-30). These rates are higher than the Light \& Gibson values of $5.5 \%$ and
$40.1 \%$, respectively (29). However, when age was controlled by making comparisons within corresponding age groups, the prevalences of overweight agreed closely with those found in the earlier study.

\section{Body mass index in relation to shift pattern, age and exposure years}

The mean BMI differed significantly $(\mathrm{t}=2.19, \mathrm{df}=1572$, $\mathrm{P}<0.05$ ) between the day shift and day-night shift personnel; the mean values were 25.8 (SD 2.9, $\mathrm{N}=787$ ) 25.5 (SD 2.7, N=787), respectively. However, this difference was attributable to the significantly higher $(\mathrm{t}=5.41, \mathrm{df}=1572, \mathrm{P}<0.001)$ mean age of the day shift group [39.8 (SD 8.9) years] relative to that of the daynight shift group [37.4 (SD 8.8) years]. When adjusted for age, the BMI difference between the day shift and day-night shift groups was no longer significant $(\mathrm{F}<1)$. Table 1 shows the raw mean BMI values and standard errors for successive age groups; subsample sizes and their standard errors are also given. These data are also shown for the day shift and day-night shift groups separately. However, neither shift pattern nor the interaction of shift pattern with age was significant. Thus the values shown for the entire sample represent the best estimate of raw age-grouped means. Mean years of exposure to shift work [day shift: 13.2 (SD 7.8) years; day-night shift: 12.6 (SD 8.1) years] did not differ significantly across the groups. Exposure years correlated significantly with BMI ( $\mathrm{r}=0.19, \mathrm{P}<0$.025).

\section{Shift pattern in relation to potential confounding variables}

The raw data shown in table 1 do not take into account the extent to which shift pattern was confounded with other predictor variables in the present study. Thus the day shift and day-night shift groups differed

Table 1. Body mass indices (BMI) across the age groups for the day shift and day-night shift groups separately and combined. (SE = standard error of the mean)

\begin{tabular}{|c|c|c|c|c|c|c|c|c|c|}
\hline \multirow{3}{*}{$\begin{array}{l}\text { Age group } \\
\text { (years) }\end{array}$} & \multicolumn{3}{|c|}{ Day shift group } & \multicolumn{3}{|c|}{ Day-night shift group } & \multicolumn{3}{|c|}{ Total sample } \\
\hline & \multirow[t]{2}{*}{$\mathrm{N}$} & \multicolumn{2}{|c|}{ BMI } & \multirow[t]{2}{*}{$N$} & \multicolumn{2}{|c|}{ BMI } & \multirow[t]{2}{*}{$\mathrm{N}$} & \multicolumn{2}{|c|}{ BMI } \\
\hline & & Mean & SE & & Mean & SE & & Mean & SE \\
\hline$<24.9$ & 38 & 23.90 & 0.36 & 51 & 24.24 & 0.37 & 89 & 24.09 & 0.26 \\
\hline $25.0-29.9$ & 74 & 25.06 & 0.33 & 131 & 24.80 & 0.22 & 205 & 24.90 & 0.18 \\
\hline $30.0-34.9$ & 102 & 24.75 & 0.23 & 137 & 25.04 & 0.22 & 231 & 24.92 & 0.16 \\
\hline $35.0-39.9$ & 153 & 25.52 & 0.24 & 137 & 25.58 & 0.23 & 290 & 25.55 & 0.17 \\
\hline $40.0-44.9$ & 170 & 26.34 & 0.23 & 143 & 25.62 & 0.23 & 313 & 26.01 & 0.16 \\
\hline $45.0-49.9$ & 139 & 26.55 & 0.23 & 121 & 26.37 & 0.23 & 260 & 26.47 & 0.16 \\
\hline $50.0-54.9$ & 75 & 26.30 & 0.35 & 52 & 26.12 & 0.37 & 127 & 26.23 & 0.26 \\
\hline$>55.0$ & 36 & 26.18 & 0.47 & 15 & 26.56 & 0.73 & 31 & 26.30 & 0.39 \\
\hline Total & 787 & 25.76 & 0.10 & 787 & 25.45 & 0.10 & 1574 & 25.61 & 0.07 \\
\hline
\end{tabular}


significantly not only in mean age, but also in distributions of job types $\left(\chi^{2}=380.6, \mathrm{df}=7, \mathrm{P}<0.001\right)$ and educational levels $\left(\chi^{2}=8.68, \mathrm{df}=3, \mathrm{P}<0.05\right)$. Thus day-night shift workers comprised $78.9 \%$ of the drillers, $43.7 \%$ of the technicians, $37.8 \%$ of the catering staff, $90.9 \%$ of the production staff, $18.8 \%$ of management, $31.3 \%$ of the administrative staff, $38.0 \%$ of the construction workers, and $35.7 \%$ of the maintenance workers. Moreover, the day-night shift personnel accounted for a larger proportion of the two lower educational levels and a smaller proportion of the two higher levels, as compared with the day-shift workers. The proportion of day-night shift workers at each of the four educational levels was $54.2 \%$ (level 0), 55.4\% (level 1), 46.7\% (level 2), and 49.7\% (level 3). Smoking rates $(35.1 \%$ day shift and $36.8 \%$ day-night shift) did not differ significantly between the two groups.

\section{Multivariate prediction of body mass index}

Table 2 shows the hierarchical multiple regression results and the unstandardized regression coefficients (B values) from the final stage of the analysis. In the initial additive model, age and each of the control variables (smoking, job type and educational level) were significant predictors of BMI. In addition, shiftwork exposure (but not shift pattern) was significant. Thus age and exposure years both made independent and positive contributions to BMI. Inclusion of the curvilinear terms contributed relatively little to the explained variance. The quadratic terms were nonsignificant and marginally significant $(\mathrm{P}<0.07)$ for age and exposure, respectively.

Linear and quadratic interactions of shift pattern with age and exposure years were entered at the final stage of the analysis. As shown in table 2, for the interaction of shift pattern with age, only the quadratic term was significant $(\mathrm{P}<0.025)$. For the interaction of shift pattern with exposure years, both the linear and the quadratic terms were significant $(\mathrm{P}<0.05$ in each case). Thus the effects of shift pattern on BMI depended significantly on both age and years of exposure to shift work. However, the joint effect of the two interactions was additive. There was no evidence of a significant threeway (shift pattern $\times$ age $\times$ exposure) term. There was also no evidence of interaction between shift pattern and job type, smoking, or educational level, which might have confounded other terms in the model.

To clarify the nature of the significant interactions between age and shift work, separate analyses were carried out for the day shift and day-night shift groups. In the day shift group both the linear $(\mathrm{F}=16.88, \mathrm{df}=1,771$, $\mathrm{P}<0.001, \mathrm{~B}=0.53)$ and the quadratic $(\mathrm{F}=8.10, \mathrm{df}=1,771$, $\mathrm{P}<0.005, \mathrm{~B}=-0.26$ ) effects of age were highly significant over and above all other terms in the model, but neither the linear nor the quadratic effects of shiftwork exposure were significant. In contrast, in the day-night shift group, the linear shiftwork exposure term was significant $(\mathrm{F}=7.24, \mathrm{df}=1,771, \mathrm{P}<0.01, \mathrm{~B}=0.41)$, while the quadratic term showed a marginal trend $(\mathrm{F}=2.61$, $\mathrm{df}=1,771, \mathrm{P}=0.10, \mathrm{~B}=-0.14)$. The effects of age were nonsignificant in this analysis, although the linear age component reached a marginal level $(\mathrm{F}=3.58, \mathrm{df}=1,771$ $\mathrm{P}<0.10, \mathrm{~B}=0.26$ ).

Considered together, these results indicate that, for day shift personnel, age is a significant predictor of BMI, but duration of shiftwork exposure does not contribute over and above age. In contrast, for day-night shift personnel, duration of exposure is the significant factor in relation to BMI, age per se having relatively little incremental effect after exposure has been taken into account. To illustrate the combined impact of age and exposure on BMI among day shift and day-night shift workers, adjusted mean BMI values were calculated for successive age points at 5-year intervals from the full regression model shown in table 2; the data are shown in figure 1 . These data assume that exposure to shift work (whether day shift or day-night shift) started at the age of 25 years (the age most closely represented in the present sample) and subsequently continued without a break. Figure 1 thus exemplifies relationships between age and BMI in the day shift and day-night shift groups taking into account the effects of age and cumulative exposure years and adjusting for all other variables in the model. As shown in figure 1, over successive age points and corresponding exposure levels, the

Table 2. Hierarchical regression analysis predicting body mass index (BMI). (NS = not significant)

\begin{tabular}{|c|c|c|c|c|}
\hline Source & $\mathrm{F}$ & $d f$ & Significance & $\mathrm{B}^{\mathrm{a}}$ \\
\hline \multicolumn{5}{|l|}{ Additive model } \\
\hline Age & 17.14 & 1.1559 & $<0.001$ & 0.26 \\
\hline Educational level & 3.86 & 3.1559 & $<0.01$ & - \\
\hline Job type & 3.39 & 7.1559 & $<0.001$ & - \\
\hline Shift pattern & $<1$ & 1.1559 & NS & 0.14 \\
\hline Exposure years & 5.76 & 1.1559 & $<0.02$ & $0.44^{\star \star}$ \\
\hline Smoking behavior & 25.98 & 1.1559 & $<0.001$ & $0.75^{\star \star \star}$ \\
\hline \multicolumn{5}{|l|}{ + Curvilinear terms } \\
\hline $\mathrm{Age}^{2}$ & 3.38 & 1.1557 & $<0.10$ & 0.06 \\
\hline Exposure $^{2}$ & $<1$ & 1.1557 & NS & -0.14 \\
\hline \multicolumn{5}{|l|}{ + Interactive terms } \\
\hline Shift pattern $x$ age & 1.91 & 1.1553 & NS & 0.26 \\
\hline Shift pattern $\times(\text { age })^{2}$ & 5.35 & 1.1553 & $<0.025$ & $-0.31^{\star \star}$ \\
\hline Shift pattern $\mathrm{x}$ exposure & 4.45 & 1.1553 & $<0.05$ & $-0.44^{\star}$ \\
\hline Shift pattern $x$ (exposure) ${ }^{2}$ & 4.44 & 1.1553 & $<0.05$ & $0.25^{\star}$ \\
\hline
\end{tabular}

Overall model: $\mathrm{F}=8.61, \mathrm{df}=20,1553, \mathrm{P}<0.001, \mathrm{R}=0.32, \mathrm{R}^{2}=0.10$

a The $B$ values are the unstandardized regression coefficients from the final simultaneous analysis.

${ }^{b}$ The continuous variables (age, and shiftwork exposure) were standardized, and the categorical variables were coded as dummy variables prior to the analysis.

${ }^{*} \mathrm{P}<0.05,{ }^{* *} \mathrm{P}<0.025,{ }^{* *} \mathrm{P}<0.001$. 


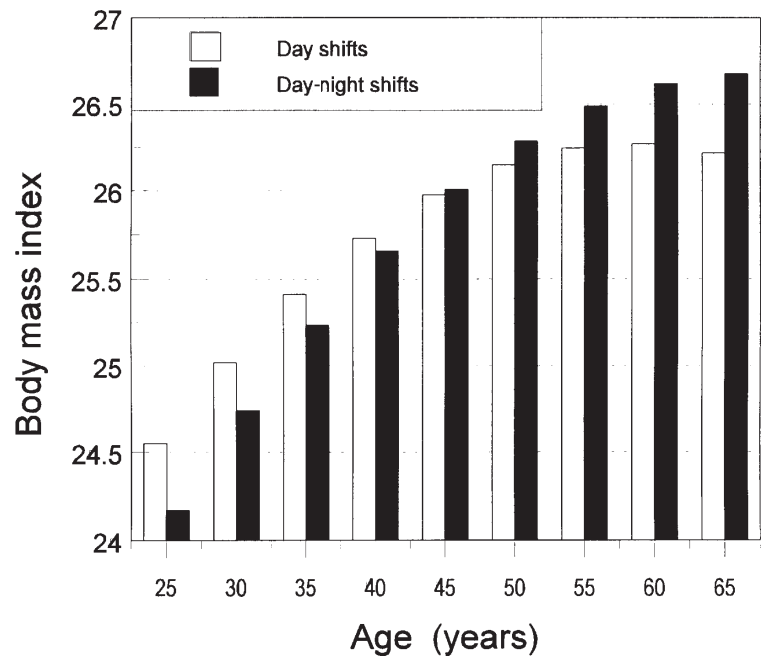

Figure 1. Body mass index for the day and day-night shift workers in relation to age, taking into account duration of shiftwork exposure. For illustrative purposes, in this figure, shift work was assumed to be undertaken from age 25 years onwards.

increase in BMI was more marked in the day-night shift group than in the day shift group. This finding reflected the added contribution of the effects of exposure years to BMI in the group working day-night shift rotating schedules. The curvilinear crossover form of the data was consistent with the absence of a main effect of shift pattern on BMI, and the significant interactions shown in table 2 .

\section{Discussion}

The results of this study are relevant to findings of high BMI levels among offshore personnel (29-31). More importantly, however, the study addresses the general question of BMI among day shift and day-night shift workers in relation to age and shiftwork exposure years, while controlling for several possible confounding factors. In particular, the findings demonstrate that age, but not duration of exposure, predicts BMI for day shift workers, while for day-night shift workers, duration of exposure is the major predictor, age per se contributing relatively little. In reviewing these results, the issues raised are considered in relation to existing findings, and some general methodological points are noted in a final section.

\section{Body mass index in relation to age}

In terms of demographic characteristics, the North Sea personnel participating in the present study were broadly representative of male offshore employees working in the UK sector (25). The mean BMI for this sample was higher than that found by Light \& Gibson (29) but, with control for age, the two sets of data showed closely similar means. Thus the present results do not suggest any general increase in body weight among offshore workers during the interval (mid-1980s to mid-1990s) between the two studies. Light \& Gibson concluded that overweight among offshore workers was significantly more prevalent than that found in the general population. However, the linear and curvilinear components of the relation between age and BMI in the present sample agreed closely with published data for a male population group (4). Nonetheless, unhealthy eating patterns (eg, high intake of fats and sugars) and the provision of meals every 6 hours round-the-clock are known to be conducive to overweight among offshore personnel (30, 31 ), and programs to increase the awareness of diet and fitness have been implemented by some companies operating in the North Sea (32).

\section{Interactive effects of age, duration of shiftwork exposure and shift pattern}

The major finding from the regression analysis was that both age and duration of exposure interacted significantly with shift pattern to predict BMI. Separate analyses for the day shift and day-night shift groups evaluated the nature of these effects. For the day shift workers, the linear and curvilinear terms representing age were highly significant in relation to BMI, but exposure duration did not contribute significantly over and above age. Thus, in this group, the pattern of results was similar to that found for population samples (4-6), and it is consistent with the fact that day shifts (even if 12 hours in duration) do not involve circadian disruption and the associated physiological, psychological, and life-style adaptation problems $(12,33,34)$. Moreover, the age (50-55 years) at which BMI reached a plateau in the day shift group agreed well with published data $(4,5)$.

In contrast, among the day-night shift workers, duration of shiftwork exposure was a highly significant predictor (longer exposure predicting higher BMI), but age per se accounted for little additional variance. Thus, in this case, exposure played the major role, while the effect of age on BMI was indirect, acting primarily through its influence on the duration of exposure. This result is consistent with previous findings that duration of exposure to shift work predicts BMI over and above the effects of age and several confounding variables (11). Changes in eating habits or a metabolic effect resulting from the circadian disruption associated with day-night shift work were suggested as explanations of the effects observed. Supporting evidence comes from a recent intervention study in which modifications of shift schedules were found to bring about favorable changes in lipids and lipoproteins known to be risk factors for cardiovascular disease (35). 
To illustrate the combined effects of shift pattern and exposure on BMI, it was assumed that shift work (whether day shift or day-night shift) was undertaken from age 25 years onwards. BMI was plotted against age for each shift pattern (figure 1), taking into account the increasing duration of exposure with increasing age. At low ages, BMI was higher among the day shift workers than among those working day-night shift schedules. However, over successive age points, BMI values increased more steeply for the day-night shift group, and the BMI of this group exceeded that of day shift workers at older ages. While cross-sectional data preclude any interpretation of the absolute levels of BMI in the two groups, the significant interaction effects reflect the different patterns across age and are consistent with the view that continued exposure to day-night shift work gives rise to increases in BMI over and above those which occur normatively among day shift workers.

The findings of this study correspond well with those of a recent small-scale study that compared day shift workers $(\mathrm{N}=36)$ with evening-night shift workers $(\mathrm{N}=49)$ with respect to weight change since starting on the shift pattern (10). The results indicated that the evening-night group reported significantly greater weight gain than the day shift group. However, current BMI levels did not differ between the groups. These findings correspond to the present results in that the two groups (mean age, early 40s, with 7-10 years of exposure) did not differ in current BMI, but the late-shift group reported a greater increase in weight over the years they had been exposed to the shift pattern.

More generally, both age and years of shiftwork exposure moderated the effect of shift pattern on BMI in the present study. This finding implies that, unless both factors are taken into account simultaneously, research outcomes will depend on the particular composition of the sample in terms of age and exposure years. Thus this result could provide an explanation for equivocal or conflicting results found in several previous studies. For instance, Niedhammer et al (9) reported that weight gain among night shift nurses was more frequent than among day-shift nurses during the second 5-year phase of their longitudinal study, but not during the preceding 5-year period. The authors noted that the effects of ageing between the first phase and the second phase could account for this result. The present results do not argue against this view but suggest that continued exposure to night shift work rather than age per se may have been the critical mediating factor.

\section{Methodological issues}

The present study depended on self-reports of current height and weight to derive the BMI values and is thus potentially open to the criticism that self-reported data are not sufficiently accurate and may be biased in ways that distort research findings. However, this issue has been widely addressed in the many published studies that use self-report methods to obtain information about height and weight $(5,6,10,36,37)$. The consensus is that, although less reliable than independent measures, self-reports are sufficiently accurate for determining BMI for research purposes $(6,10,38,39)$. This view is further supported by the close agreement between the BMI values reported in the present study and those from an earlier study of offshore workers in which independent anthropometric measures were made (29).

The limitations of cross-sectional survey data, particularly the problems of drawing causal inferences, must also be considered. In this respect, however, the nature of the offshore work environment serves to clarify some ambiguities of interpretation. Thus, although selection and survival effects (ie, self-selection into or out of shift work in ways that may act to confound comparisons between the two groups) cannot be ruled out as potential explanations for the present findings, it is unlikely that they could entirely account for the results found. To attribute the differential rate of BMI increase observed across age for the day shift and day-night shift groups to preexisting differences and differential survival, one would have to argue that personnel with low BMI levels are more likely to select themselves into day-night shift work at a young age, but disproportionately likely to select themselves out at each subsequent age point.

In this context, the possibility that day-night shift workers may differ from day shift workers in previous or current illness at the application and selection stages is relevant, although empirical evidence suggests that self-selection into shift work relates to sleeping habits rather than to health status (40). Moreover, in the offshore work setting, all personnel are required to meet rigorous standards of physical and mental health (41). Thus offshore workers can be regarded as an exceptionally "healthy worker" group in which health status is more favorable than in the general working population (42) and is independent of job type and shift pattern. The possibility that the present findings are attributable to differences in initial health status is therefore less likely than in studies of onshore occupations which impose less rigorous health standards. Furthermore, older day-night shift personnel wishing to transfer to day shifts for health reasons are more likely to seek onshore employment than to remain offshore working 12-hour shifts and demanding schedules, irrespective of shift pattern. These points, and the fact that the present findings are in line with existing evidence relating BMI to day-night shift work, strengthen the conclusion that continued exposure to day-night shift work gives rise to increases in BMI over and above those experienced by day shift workers. However, longitudinal research, in which 
baseline data are collected from shiftworkers at initial recruitment with subsequent follow-up, would be potentially valuable.

A further issue raised in the literature is whether the unfavorable health outcomes found to be associated with day-night shift work, particularly cardiovascular disease $(16,17)$, may be due not to the adverse effects of circadian disruption, but rather to psychosocial work conditions $(19,43)$. Thus some evidence suggests that perceptions of the physical and psychosocial work environment differ across shift patterns (44). Two points argue against this explanation for the present findings. First, substantial variation in psychosocial work measures is attributable to broad differences between different types of jobs $(25,45,46)$. Thus, in the present study, the inclusion of job type in the predictive model served to control for much of the potential effect of psychosocial work factors. Second, there were no significant correlations between BMI levels and measures of the perceived work environment in the present sample (26). Thus there was no evidence to suggest that the present findings were attributable to perceived work conditions rather than to shift effects.

General life-style differences between day shift and day-night shift workers may also bias observed relations between shift work and BMI. In particular, shift schedules involving night work may affect eating habits and leisure activities $(9,12-14)$. Food intake and exercise were not assessed in the present survey, but the inclusion of diet, alcohol intake, physical activity, and other life-style factors would be valuable in future studies. However, in relation to diet and life-style factors, the offshore setting of the present study had several advantages over onshore settings. Thus all offshore personnel work and live in the same environment, with the same meal times and food choices (including absence of alcohol), recreational facilities, sleeping accommodation, and work-leave patterns. Life-style differences that may contribute to the effects observed for onshore samples are therefore less pertinent offshore. Furthermore, all offshore personnel are exposed to 12-hour shifts. Thus the primary difference between the day shift and daynight shifts offshore is that day work does not necessitate circadian adaptation. Indeed, in that offshore routines tend to facilitate adaptation to day-night shift work (47-49), the present findings may underestimate the effects of day-night shift work onshore.

\section{Acknowledgments}

The research reported in this article was funded by the UK Health and Safety Executive.

The assistance of Melanie Clark in the collection and processing of data is gratefully acknowledged.

\section{References}

1. Rosengren A, Wedel H, Wilhelmsen L. Body weight and weight gain during adult life in men in relation to coronary heart disease and mortality: a prospective population study. Eur Heart J 1999;20:269-77.

2. Solomon CG, Manson JE. Obesity and mortality: a review of the epidemiologic data. Am J Clin Nutr 1997;66:1044S-50S.

3. Froom P, Melamed S, Kristal-Boneh E, Gofer D, Ribak J. Industrial accidents are related to relative body weight: the Israeli CORDIS study. Occup Environ Med 1996;53:832-5.

4. Grinker JA, Tucker K, Wokonas PS, Rush D. Body habitus changes among adult males from the normative aging study: relations to aging, smoking history and alcohol intake. Obes Res 1995;3:435-46.

5. Cairney J, Wade TJ. Correlates of body weight in the 1994 national population health survey. Int J Obes Relat Metab Disord 1998;22:584-91.

6. Sundquist J, Johansson SE. The influence of socioeconomic status, ethnicity and lifestyle on body mass index in a longitudinal study. Int J Epidemiol 1998;27:57-63.

7. Brisson C, Larocque B, Moisan J, Vezina M, Dagenais GR. Psychosocial factors at work, smoking, sedentary behavior, and body mass index: a prevalence study among 6995 white collar workers. J Occup Environ Med 2000;42:40-6.

8. Shields M. Long working hours and health. Health Rep 1999;11:33-47.

9. Niedhammer I, Lert F, Marne MJ. Prevalence of overweight and weight gain in relation to night work in a nurses' cohort. Int J Obes Relat Metab Disord 1996;20:625-33.

10. Geliebter A, Gluck ME, Tanowitz M, Aronoff NJ, Zammit GK. Work-shift period and weight change. Nutrition 2000; $16: 27-9$.

11. van Amelsvoort LG, Schouten EG, Kok FJ. Duration of shiftwork related to body mass index and waist to hip ratio. Int J Obes Relat Metab Disord 1999;23:973-8.

12. Tepas DI. Do eating and drinking habits interact with work schedule variables? Work Stress 1990;4:203-11.

13. Sudo N, Ohtsuka R. Nutrient intake among female shift workers in a computer factory in Japan. Int J Food Sci Nutr 2001; 52:367-78.

14. Lennernas M, Hambraeus L, Akerstedt T. Shift related dietary intake in day and shift workers. Appetite 1995;25:25365.

15. Morikawa Y, Nakagawa H, Miura K, Ishizaki M, Tabata M, Nishijo M, et al. Relationship between shift work and onset of hypertension in a cohort of manual workers. Scand J Work Environ Health 1999;25:100-4.

16. Knutsson A, Hallquist J, Reuterwall C, Theorell T, Akerstedt T. Shiftwork and myocardial infarction: a case-control study. Occup Environ Med 1999;56:46-50.

17. Tenkanen L, Sjöblom T, Härmä M. Joint effect of shift work and adverse life-style factors on the risk of coronary heart disease. Scand J Work Environ Health 1998;24:351-7.

18. Bøggild H, Knutsson A. Shift work, risk factors and cardiovascular disease. Scand J Work Environ Health 1999;25:8599.

19. Härmä M. Shift work and cardiovascular disease - from etiologic studies to prevention through scheduling [editorial]. Scand J Work Environ Health 2001;27:85-6.

20. Åkerstedt T. Psychological and psychophysiological effects of shift work. Scand J Work Environ Health 1990;16 suppl 1:67-73. 
21 Marquie JC, Foret J, Queinnec Y. Effects of age, working hours, and job content on sleep: a pilot study. Exp Aging Res 1999;25:421-7.

22. Härmä M, Hakola T, Akerstedt T, Laitinen J. Age and adjustment to night work. Occup Environ Med 1994;51:568-73.

23. Koller M. Health risks related to shift work: an example of time-contingent effects of long-term stress. Int Arch Occup Environ Health 1983;53:59-75.

24. Hardy R, Wadsworth M, Kuh D. The influence of childhood weight and socioeconomic status on change in adult body mass index in a British national birth cohort. Int J Obes Relat Metab Disord 2000;24:725-34.

25. Parkes KR, Clark MJ, Payne-Cook E. Psychosocial aspects of work and health in the North Sea oil and gas industry, part IV: the offshore environment in the mid-1990's: a survey of psychosocial factors. Sudbury (UK): HSE Books, 1997. OTH 96530.

26. Parkes KR. Shiftwork, job type, and the work environment as joint predictors of health outcomes. J Occup Health Psychol 1999;4:256-68.

27. Cohen J, Cohen P. Applied multiple regression/correlation analysis for the behavioral sciences. Hillsdale (NJ): Lawrence Erlbaum Associates, 1983.

28. Aiken LS, West SG. Multiple regression: testing and interpreting interactions. London: Sage Publications, 1991.

29. Light IM, Gibson M. Percentage body fat and prevalence of obesity in a UK offshore population. Br J Nutr 1986;56:97104.

30. Oshaug A, Ostgard LI, Trygg KU. Diet among oil-workers on off-shore oil installations in the Norwegian sector of the North Sea. Br J Nutr 1992;68:11-9.

31. Horsley H, MacKenzie IG. Lifestyle survey amongst North Sea oil workers. In: Gardner R, editor. Occupational health offshore. Aberdeen (UK): HSE Books, 1996:161-79.

32. Lobban P. The Shell expro lifestyle programme. In: Gardner $\mathrm{R}$, editor. Occupational health offshore. Aberdeen (UK): HSE Books, 1996:181-6.

33. Härmä MI, Ilmarinen JE. Towards the 24-hour society new approaches for aging shift workers? Scand J Work Environ Health 1999;25:610-15.

34. Richardson G, Tate B. Hormonal and pharmacological manipulation of the circadian clock: recent developments and future strategies. Sleep 2000;23 suppl 3:s77-s85.

35. Bøggild H, Jeppesen HJ. Intervention in shift scheduling and changes in biomarkers of heart disease in hospital wards. Scand J Work Environ Health 2001;27:87-96.

36. Rosmond R, Lapidus L, Bjorntorp P. The influence of occu- pational and social factors on obesity and body fat distribution in middle-aged men. Int J Obes Relat Metab Disord 1996;20:599-607.

37. Yarnell JW, Patterson CC, Thomas HF, Sweetnam PM. Comparison of weight in middle age, weight at 18 years, and weight change between, in predicting subsequent 14 year mortality and coronary events: Caerphilly prospective study. J Epidemiol Community Health 2000;54:344-8.

38. Stunkard AJ, Albaum JM. The accuracy of self-reported weights. Am J Clin Nutr 1981;34:1593-9.

39 Rowland ML Self-reported weight and height Am J Clin Nutr 1990;52:1125-33.

40 Knutsson A, Akerstedt T The healthy-worker effect: selfselection among Swedish shift workers Work Stress 1992;6:163-7.

41. UK Offshore Operators Association. Guidelines for medical aspects of fitness for offshore work. London: UK Offshore Operators Association, 1995.

42. Parkes KR. Psychosocial aspects of stress, health and safety on North Sea installations. Scand J Work Environ Health 1998;24:321-33.

43. Åkerstedt T, Knutsson A. Cardiovascular disease and shift work [editorial]. Scand J Work Environ Health 1997;23:2412.

44. Bøggild H, Burr H, Tüchsen F, Jeppesen HJ. Work environment of Danish shift and day workers. Scand J Work Environ Health 2001;27:97-105.

45. Haynes CE, Wall TD, Bolden RI, Stride C, Rick JE. Measures of perceived work characteristics for health services research: test of a measurement model and normative data. Brit J Health Psychol 1999;4:257-75.

46. Karasek RA, Brisson C, Kawakami N, Houtman I, Bongers P, Amick B. The Job Content Questionnaire (JCQ): An instrument for internationally comparative assessments of psychosocial job characteristics. J Occup Health Psychol 1998;3:322-55.

47. Parkes KR. Sleep patterns, shiftwork, and individual differences: a comparison of onshore and offshore control-room operators. Ergonomics 1994;37:827-44.

48. Bjorvatn B, Kecklund G, Akerstedt T. Rapid adaptation to night work at an oil platform, but slow readaptation after returning home. J Occup Environ Med 1998;40:601-8.

49. Rajaratnam SMW, Arendt J. Health in a 24-h society. Lancet 2001;358:999-1005.

Received for publication: 28 June 2001 